\title{
The Effects of Internet-Based Instruction on Student Learning
}

\author{
Dr. Scott B. Wegner, Associate Professor \\ Department of Educational Administration \\ \#8 Monroe Hall \\ Southwest Missouri State University \\ 901 South National \\ Springfield, Missouri 65804 \\ Phone: 417-836-5554 \\ Fax: 417-836-5997 \\ E-mail: sbw851f@mail.smsu.edu \\ Dr. Ken C. Holloway, Assistant Professor \\ Department of Educational Administration \\ \#8 Monroe Hall \\ Southwest Missouri State University \\ 901 South National \\ Springfield, Missouri 65804 \\ Phone: 417-836-5554 \\ Fax: 417-836-5997 \\ E-mail: kch972f@mail.smsu.edu \\ Edwin M. Garton, Graduate Student \\ College of Education \\ 308 Hill Hall \\ Southwest Missouri State University \\ 901 South National \\ Springfield, Missouri 65804
}

\begin{abstract}
The practice of using technology to deliver coursework in higher education has seen a veritable explosion. The use of technology has not only created new opportunities within the traditional classroom but has also served to expand learning experiences beyond the popular notion of "classroom." Indeed, "distance learning," especially utilization of the Internet, is becoming a widely used delivery alternative at universities nationwide.

In many instances the change to an Internet-based delivery system has been instituted with little or no consideration of the impact on student learning. This paper presents data from a twosemester study of the effects of distance learning on student achievement as well as the impact of distance learning on student attitudes concerning their learning experiences. Students' test scores and satisfaction survey results from an Internet-based test group were compared to a control group whose instructional opportunities were from traditional, in-class models. Researchers found no significant difference between the test scores of the two groups. Additionally, while statistically significant data could not be produced in the area of student perceptions, general observations supported that, overall, students in the experimental group had a more positive feeling about their experience than the control group.
\end{abstract}




\section{KEYWORDS}

Distance learning, Computer-mediated instruction, Teaching/learning strategies, Problem-based learning.

\section{INTRODUCTION}

The role of technology in the delivery of instruction at universities has been truly explosive. While relatively unheard of just ten years ago, a key word search of the Internet today using "Internet-based distance learning" yields literally hundreds of sites devoted to the subject. Opportunities to receive coursework via the Internet exist routinely at most universities while the opportunity to pursue an entire degree program is becoming a reality at more and more institutions worldwide. The prognostications made just a few short years ago, that the Internet would soon be as common as the telephone or television as a means of communication have rapidly become a reality. Indeed, use of the Internet for delivery of distance education is active at all levels of the educational hierarchy and looks to maintain a general upsweep [1].

The marriage of technology and higher education is set, and it appears that it will enjoy some longevity. It was forecast just recently that, by the year 2000, we would be instructing more students over a far greater range of technologies than ever previously imagined [2]. We are at the threshold of that prognosis and it looks very much like it will easily be attained. However, despite all of the economic promise, the convenience and expanded accessibility, little has been researched on the quality of educational opportunities that Internet-based distance learning presents. While there are several studies [3], [4] which examined telecommunication-based courses versus traditional formats (finding no significant differences in GPAs of students in either format), there is very little data concerning the delivery of distance learning in one of the fastest growing modes today: over the Internet.

Concerns about distance learning opportunities have been addressed in most of the literature. Lack of technological expertise on the part of both teacher and student [5], resistance to change on the part of faculty [2], student passivity [6], hardware limitations [7] and learner isolation [8] are but a few of the perceived drawbacks to distance learning. While they represent legitimate areas of concern, for the most part, these problems relate to training and technology issues that have fairly obvious remedies. Less obvious in the literature is the effect distance learning over the Internet has on student achievement.

\section{THE STUDY}

The dilemma that faced these researchers was the same that is facing most university instructors today. If it is a given that Internet-based distance learning is here to stay and that most of the delivery issues previously discussed in the literature (i.e., hardware compatibility, student isolation and technological training) could be remediated, then would there be any significant difference in student achievement, as measured by teacher-prepared tests, between students taking a course in an Internet-based environment versus those who received instruction in the more traditional, in-class model? Additionally, these researchers were interested in whether there would be any difference in the perceptions of these two groups about their learning opportunities as measured by student surveys and student evaluation instruments. 


\section{A. Methodology}

The population selected to test our questions was comprised of graduate students in the Spring and Fall sections of a curriculum design and evaluation course. Students were allowed to selfselect into either the traditional classroom section or into the experimental Internet-based section. The control group $(\mathrm{N}=17)$ received instruction in a traditional lecture, question-answer, smallgroup activity format. Instruction was delivered during sixteen, three-hour periods, typical of graduate level education within the graduate degree programs at the institution. The experimental group $(\mathrm{N}=14)$ attended no classes on-campus except to present their final products. Additionally, the instructor met with members either on-campus or on-site to provide basic training for use of the technologies involved in the class. These sessions included training on e-mail, videoconferencing using CUSeeMe software, and NetMeeting software as well as more traditional technologies such as the telephone and fax.

Members of both the experimental and control groups were primarily educators who were currently employed as classroom teachers in rural schools. All members were part-time students in a masters degree program associated with principal certification. There was a similar distribution of students in small and large school districts with the range of district enrollments going from just under 500 students to just over 22,000 . The bulk of the students $(64 \%$ of the experimental group and 53\% of the control group) were from school districts between 2700 and 7100 students.

The researchers felt that in order to provide comparable learning opportunities for the experimental group, an alternative, Internet appropriate instructional model would have to be developed. Based on a review of the literature, a problem-based model was selected. Problembased learning models have been in place in the medical field for decades and some authors speculate that the model is now used in well over $80 \%$ of all medical schools in the United States [9]. Problem-based learning has been defined as:

...learning that results from the process of working toward the understanding or resolution of a problem. The problem is encountered first in the learning process and serves as the focus for application of problem solving or reasoning skills, as well as the search for or study of information or knowledge needed to understand the mechanisms responsible for the problem and how it might be resolved. [10]

Researchers followed the recommendations of the research in establishing the problems to maximize the chances that students would be exposed to the same types of knowledge bases that the in-class group would receive and that would also expose them to similar participation opportunities. In developing the problem-based learning experiences a synthesis of research revealed that:

1. The starting point of the learning is a problem [9].

2. The problem should be one that students are apt to face in the future [9].

3. Subject matter is organized around the problem rather than by discipline [11].

4. The teacher best supports the lesson through problem formulation.

5. Open-ended and divergent questioning on the part of the instructor is crucial to

1. the problem-solving process [12].

Each problem included a list of focusing questions, product specifications that provided a general description of the product to be generated, key terms and concepts, a list of resources, and a scoring guide for assessing the final product. It is important to note that while students had 
access to the textbook used by the control group, no mandatory reading assignments were given. Also, materials which were given to the control group as regular class handouts were not made available to the experimental group until they made a request for the type of information contained in them. Similarly, consistent with the problem-based learning design utilized, teacher expertise was accessed by the experimental group through a specific request for information. In all cases, assistance to the experimental group was delivered electronically.

\section{B. Results}

To assess student achievement of the course knowledge base, an identical 100-point exam, comprised of objective, short answer and essay questions was administered to both groups. The tests were administered during the $15^{\text {th }}$ week of class, monitored by the instructor who also corrected and graded all exams. Table 1 shows the descriptive data for both groups of test takers.

\begin{tabular}{|l|l|l|l|l|}
\hline \multicolumn{1}{|c|}{ Group } & N & Mean & Range & Std. Deviation \\
\hline Control & 17 & 92.64 & $85-100$ & 4.1824 \\
\hline Experimental & 14 & 91.57 & $84-97$ & 3.7358 \\
\hline \multicolumn{5}{|c|}{ Table 1. Descriptive Statistics. } \\
\hline
\end{tabular}

Means for the two groups were close, as were the ranges and standard deviations. A study of the test score frequencies showed that the only perfect score was in the control group. Additionally, while there were four scores above 95 in the control group, there were only two scores above 95 in the experimental group. It is of interest that an item analysis of the test showed that overall, the majority of the discrepancy in scores could be traced to three short-answer questions. These three questions were related to lecture material gathered from a specific author's interpretation of curriculum integration. Removal of those three questions from the test would have resulted in the experimental group actually outscoring the control group. Additionally, the experimental group outscored the control group on the objective portion of the test though the difference was not statistically significant.

A t-Test for Independent Samples was administered to the test scores to determine whether there was any statistical significance between the overall test scores of the two groups. Table 2 presents that data.

\begin{tabular}{|c|c|c|l|l|l|}
\hline Group & Sample size & Means & Std. Dev. & t - Value & Probability \\
\hline Control & 17 & 92.64 & 4.1824 & -0.7473 & 0.2305 \\
\hline Experimental & 14 & 91.57 & 3.7358 & \\
\hline \multicolumn{5}{|c|}{ Table 2. T-Test for Independent Samples. } \\
\hline
\end{tabular}

The t- value of -0.7473 and probability factor of .2305 were not sufficient to prove a significant difference between the test scores of the control group and the experimental group.

\section{Student Ratings on Evaluations}

Perceptions of the class and their learning opportunities provided, though not statistically significant, interesting descriptive data. For instance, on the question "The over all quality of this course ranked among the top $20 \%$ of courses I have taken," (1= Strongly agree, $2=$ Agree, $3=$ No Opinion, 4=Disagree and 5= Strongly Disagree) the control group mean was 1.8 while the experimental group was 1.2. Additionally, on the question "This course offered me an intellectual challenge," the control group mean was 1.45 while the experimental group mean was 1.15. This trend of higher ratings continued on all questions related to instructional delivery with only a few exceptions. On the question "The instructor presented the course in a clear and 
organized manner," for example, the control group mean was 1.64 while the experimental group mean was 2.89 .

There was a clear pattern that the students in the experimental group had a more positive feeling about the course. In fact $80 \%$ of the course evaluation items relating to instructional delivery and learning opportunities received higher ratings from the experimental group than from the control group. The items on which the experimental group ratings were lower dealt with instructorcentered delivery issues (use of class time) and the utility of the textbook. On these types of items the preponderance of experimental group responses were $3=$ No Opinion.

\section{Student Comments - Control Group}

As in the case of student evaluations, student comments from the two groups yielded data that provided useful, though statistically insignificant, insights. Comments from the control were relatively few (only $41 \%$ of the class offered either positive or negative criticisms), but raised interesting points. First, most negative responses (as represented in Table 3) dealt with three issues: room conditions, time required and assignments/tests.

\section{Negative Comments}

In regard to room condition, $23 \%$ of the control group responded that the room was either too cold or too hot, the seats were uncomfortable or the general room condition was thought to be dirty. Seventeen percent of the control group responded about issues related to time, indicating that they felt they were not let out of class early enough or that the course work required more time than they felt a three-hour course should warrant. Finally $23 \%$ of the students in the control group showed concern about the class assignments and/or tests. Student comments typically included remarks about the amount of information required to be memorized, the extensive requirements for the project or the lack of "hands on" opportunities on assignments. It should be noted that an analysis of comments made by students in this class over the five years previous the study could be basically grouped into the same categories with nearly the same per cent of class members responding. Evidently the instructor had little control over the maintenance of the room, little sympathy for dismissing class early and a tendency to expect a large assimilation of knowledge.

\begin{tabular}{|c|c|c|c|}
\hline Category & Room condition & Time required & Assignments/Tests \\
\hline \% of Class (N) & $23 \%(4)$ & $17 \%(3)$ & $23 \%(4)$ \\
\hline
\end{tabular}

Table 3. Control Group Negative Comments. 


\section{Positive Comments}

Positive comments from the control group (as represented in Table 4) were basically to praise the knowledge base of the instructor and the usefulness/timeliness of the information presented. Thirty five percent of the class made comments which stated that the instructor (or his knowledge base) for the class was the most positive aspect. No other categories of positive comments were evident. This statistic is telling because the primary delivery of instruction was a traditional teacher-centered format. This mode of delivery has the feature of making the instructor the most salient aspect of the course. The instructor's knowledge and experiences, as well as his/her ability to communicate through lecture or classroom activities, are the primary basis for a successful class. This is consistent with the time-honored notion that the instructor makes the class. Again, analysis of previous evaluation comments from students in this course showed a similar trend. While there were a spattering of remarks about course relevance and project work, the greatest preponderance of positive comments were about the instructor. This occurred even though all evaluations were confidential and the instructor was not allowed access to the results until after course grades had been filed as is typical for most university evaluation procedures.

\begin{tabular}{|l|c|}
\hline Category & Instructor Expertise/Content \\
\hline \% of Class (N) & $35 \%(6)$ \\
\hline \multicolumn{2}{|c|}{ Table 4. Control Group Positive Comments. } \\
\hline
\end{tabular}

Table 4. Control Group Positive Comments.

\section{E. Student Comments - Experimental Group}

Comments from the experimental group were much more plentiful (100\% of the group gave written input on both positive and negative issues). Negative responses (see Table 5) dealt with three basic issues: Lack of instructor direction/contact, content/prerequisites, and technological issues.

\section{Negative Comments}

Lack of contact with the instructor was the chief concern mentioned in 50\% of the experimental group responses. Twenty-nine per cent of the experimental group responses indicated that lack of content background/prerequisites was a concern and a relatively small number (7\%) indicated that technology training was an area of concern. The lack of instructor direction was expected as the basic nature of the Internet learning creates barriers to the type of interaction experienced in traditional classrooms. Additionally, the problem-based learning instructional model utilized with the experimental group features a more student-centered approach to learning. Instructors are not expected to give answers and directions, they are expected to assume a supportive but more passive role. Students, not used to this method of inquiry, evidently experienced some discomfort in making the transition from teacher-centered to student-centered learning.

\begin{tabular}{|l|c|c|c|}
\hline Category & Lack of Direction & Lack of Content & Technology \\
\hline \% of Class (N) & $50 \%(7)$ & $29 \%(4)$ & $7 \%(1)$ \\
\hline
\end{tabular}

Table 5. Experimental Group Negative Comments. 


\section{Positive Comments}

Positive comments from the experimental group could be categorized in four main areas: Practicality/Performance-based, Technology, Group Processes and Convenience. The authentic, performance-based nature of the class was seen as the biggest positive as indicated by the high response rate $(71 \%)$ of the experimental group. Thirty-six percent of the class indicated that the chance to use technology in a productive way was a plus and $21 \%$ stated that the convenience of not having to travel and having flexible work hours was a major advantage. Interestingly, $36 \%$ of the experimental group cited the opportunity to solve problems, use consensus building skills, exercise autonomous learning as a group and communications skill as competencies gained over what they normally would get through traditional instructional delivery models.

\begin{tabular}{|l|c|c|c|c|}
\hline Category & $\begin{array}{c}\text { Performance } \\
\text { Orientation }\end{array}$ & Technology & Group Skills & Convenience \\
\hline \% of Class (N) & $71 \%(10)$ & $36 \%(5)$ & $36 \%(5)$ & $21 \%(3)$ \\
\hline \multicolumn{4}{r}{ Table 6. Experimental Group Positive Comments. }
\end{tabular}

In analyzing the positive responses of the class, the researchers felt that comments concerning the authentic, performance orientation of the course could not be directly attributed to the use of an Internet-based delivery system. The researchers felt that the authentic nature of the course was more a feature of the problem-based instructional system employed by the instructor. However, given the comments about group skill development, researchers found a basis in the literature that substantiated a relationship between the use of technology-based delivery systems and the cultivation of group processing skills. Previous research has established that computer-based instruction facilitates "learning how-to-learn skills" such as collaboration, problem solving, locating and using information and communication skills [13]. There is at least some indication in this study that students developed and utilized skills independent of instructor directives or problem design. It is the belief of the researchers that these skills may be inherent in Internetbased instruction. As one student commented, "The use of Internet to explore and find information and the interaction of the group to arrive at answers coupled with the usefulness of the product is what I liked best about the course."

\section{CONCLUSIONS}

Despite the small sample size and heavy reliance on anecdotal information, the study yielded several interesting conclusions. First, there was no significant difference in test scores between the two groups despite the experimental groups not attending even a single on-campus lecture. This was amazing to those associated with the study, all of whom half-hoped to validate the significance of the class lecturer to the learning process. This is not to say that Internet-based instruction was not heavily impacted by the instructor. It only suggests that role of the instructor changed for the Internet-based instruction.

Instruction on the Internet accentuates the "student as worker" and the "teacher as coach" paradigms. The role of the instructor becomes one of preparing the instructional environment, anticipating the needs of the students in advance and providing contingencies. They become Socratic questioners, resource providers and motivators. Instructors respond to and accommodate learners in assisting them to develop their own meaning for the material rather than interpreting the material for them. It poses a real challenge to traditional thinking, or at least traditional practice, but if distance learning on the Internet is to be successful, it is a paradigm shift that must be made. 
Another conclusion relates to student perceptions about their Internet learning opportunities. While statistically significant data could not be produced, general observations supported that, overall, students in the experimental group had a more positive feeling about their experience than the control group. More students were willing to respond to surveys, they provided higher marks on the evaluation sheets and they provided more positive comments than the control group. Surprisingly, convenience, which researchers anticipated most students would list as a positive, was only mentioned by $7 \%$ of the students.

Was the novelty of the experience responsible for student's positive feelings? This question was untested and would make an interesting premise for future study. Was it the problem-based approach that generated the difference in feelings about the course? Possibly, though it was the contention of the researchers from the beginning that it would take a well-planned and distancelearning-appropriate instructional design to provide equal opportunity for the experimental group. It is the belief of the researchers that Internet-based instruction is at worst a neutral factor regarding students' perceptions about their learning. No student in the experimental group stated that they would never take another Internet-based course nor were indications of dissatisfaction with experiences or technologies provided. It is our belief, as is the case with any instructional delivery model, there will be some that will not be comfortable with nor particularly like Internetbased courses. But then what instructional delivery system can boasts a $100 \%$ satisfaction rate!

In summary, Internet-based delivery of coursework appears to have no negative effect on student achievement or on students' perception of their learning. This is good, since the proliferation of Internet-based courses shows no sign of abatement in the near future. It is important, however, to recognize that to ensure student success in Internet-based courses requires the same careful attention to instructional design, the same level of diligence on the part of the instructor and the same opportunity for meaningful communication that traditional in-class models require. Use of technology in any capacity does not guarantee academic success, but indications from this study suggest that it dos not necessarily have any significant negative effects.

\section{REFERENCES}

1. Plotnik, E., Trends in Educational Technology 1995. ERIC Digest, ERIC Clearinghouse on Information and Technology, Syracuse New York. ED398861, 1996.

2. Parrot, S., Future Learning: Distance Education in Community Colleges. Eric Digest. ERIC Clearinghouse for Community Colleges, Los Angeles California. ED385311, 1995.

3. Nixon, D. E., Simulteaching: Access to Learning by Means of Interactive Television. Community Junior College Quarterly of Research and Practice, 16 (2), 167-175. 1992.

4. Sercy R.D., Grade Distribution Study: Telecourses Vs. Traditional Courses. Manuscript prepared for the Calhoun Telecourse Steering Committee, Decatur, Alabama: Calhoun Community College, ED 362 251, 1993.

5. Wegner S. B., Holloway, K. C. and Crader, A. B., A Problem-based Approach on the WorldWide-Web. Resources in Education, ERIC Clearinghouse for Teaching and Teacher Education. ED 414262 1998, 1997.

6. Filipczak, B., Putting the Learning Into Distance Learning, Training 32, No.10 111-118. EJ511 $253,1995$.

7. Kerka, S.,Distance Learning, the Internet, and the World Wide Web. ERIC Digest. ERIC Clearinghouse on Adult, Career and Vocational Education, Columbus Ohio. ED395214, 1996.

8. Kubala, T., Addressing Student Needs: Teaching on the Internet, T.H.E. Journal 25 (8) 71-74, 1998. 
9. Bridges, E. M., and Hallinger, P., Problem-Based Learning in Medical and Managerial Education, In P. Hallinger, K. Leitwood, and J. Murphy, (Eds), Cognitive Perspectives on Educational Leadership, New York, Teachers College Press, 1993.

10. Barrows, H. S., and Tamblyn, R. M., Problem-based Learning: An Approach to Medical Education. New York: Springer Publishing Co., 1980.

11. Bridges, E. M., Problem-based Learning in Management Education. Paper presented at George Peabody University, Nashville, TN, January 1990.

12. Whitman, N. and Schwenk, L., Problem-solving in Medical Education: Can it be

13. Taught? Current Surgery, 453-459, November-December 1986.

14. Eastmond, D. V., Alone but Together: Adult Distance Study Through Computer Conferencing, Cresskill, NJ: Hampton Press, 1995. 